\title{
Prof. Honório Monteiro ${ }^{\star}{ }^{\star}$
}

\section{Benedicto de Siqueira Ferreira}

Não poucas vezes são as circunstancias que revestem um fato, que lhe dão relevo e lhe emprestam significação especial.

Se a presença do professor Honónio Monteiro na Faculdade de Direito de São Paulo, nesta Casa que é sua, que é nossa pelo muito que lhe queremos, é evento rotineiro, te-lo aqui como Ministro do Trabalho a comemorar, com uma conferencia, a data que é o ocaso de uma Ditadura e marco inicial da reconstitucionalisação do país, nos enche de jubilo e de esperanças; jubilo pela felís escolha governamental, esperanças pois a mesma corresponde a nossos anceios.

Atentai, senhores, para a conjunção das circunstancias: à data tão memoravel corresponđe no espaço, como cenário para sua comemoração, a Faculdade de Direito de São Paulo que, durante a noite tenebrósa de uma autocracia cheia de pesadelos e sobresaltos, foi guardiã incorruptivel da democracia, o convento onde, como nos mosteiros medievaes repositórios de toda a cultura da época, se acolheu a liberdade e se refugiou a conciencia democratica da Nação, como a verdadeiro sacrário, não maculado siquér pela efigie do ditador - fato antes unico que raro na história desse angustioso periodo - e que tem, como bastião a defende-lo, o lendário Largo de São Francisco que a nossa

(') Discurso proferido na sessão solene da Congregação de Professores em homenagem ao prof. Honório Monterro, por motivo da sua nomeação para Ministro do Trabalho. 
mocidade para sempre imortalisou, "tingindo-o com o rubi de nossas cores", na frase lapidar de Mario MazaGão. (1)

Foi este recinto tão impregnado ainda de recordações, pungentes umas, alegres e alviçareiras outras que o snr. Ministro do Trabalho escolheu para dissertar sobre a democracia, palavra anatematisada inscrita no Index do Totalitarismo que no dizer de Manorlesco (2) significa partido unico e pois ausencia de liberdade; verdadeira blasfemia em patria infelís onde nem siquér partido unico se admitia. .

Esta conjunção de circunstancias nos enche de esperanças e de fé no futuro da democracia brasileira.

$E$ isto, senhores, em verdade, em verdade vos digo pois, ha bem pouco tempo, no instante do Adeus simbólico simbólico, sim, porque desta Casa jamais se apartam seus filhos espirituaes - no instante do Adeus simbólico à ultima pleiade de bacharelandos que daqui partiu, cerimonia a que, como professor, e mais ainda, atraido pela voz do sangue (3), assistiu o atual Ministro do Trabalho, assim recitava eu, como paraninfo, o Credo Democratico aos nóveis colegas:

"Não duvideis jamais das virtudes da Democracia si aqui ou acolá, como consequencia da imperfeição humana, não corresponder o cenário politico de nossa Patria aos vossos ideaes.

De inicio isto frequentemente ocorrerá pois o povo, afastado criminósamente por largos anos da gestão da cousa publica, terá que aprender de novo a ser cidadão.

Si alguem, em momento de desanimo ou de desespero se mostrar saudoso da aparente ordem e disciplina que reinava nos paises governados pela força, lembrai-lhe que ninguem jamais aprendeu a ser livre acorrentado em uma senzala.

A alegria da libertação poderá, quando se rompem as barreiras da opressão, conduzir a excéssos que toquem às raias da licenciosidade, mas só usufruindo a liberdade é que se aprende a respeital-a. 
Democracia é cultura e escóla de civismo.

Não basta, porem, que se reestruture o país nos moldes democraticos: mistér se faz que a esse corpo organisado se dê uma nóbre alma, se imprima mentalidade democratica.

Mas qual o artifice dessa óbra quasi divina, qual o sopro que irá vivificar esse organismo comunicando-lhe a chama ardente do Ideal?

A vóz do jurista, a vóz d'aquele que habituado ao trato de nórmas que regem a vida social, bem sabe que o remédio não é a demagogia mas a sinceridade, não é a discussão estéril mas a disciplina férrea do trabalho, não é o aleive reciproco mas o respeito mutuo, não é a ameaça mas o conselho e principalmente a mais impressionante modalidade deste: o exemplo." (4)

A estes anceios, senhores, corresponde hoje a certez: de que o Ministério do Trabalho será uma nóva catedra, da qual a vóz do jurista, com a noção exata da responsabilidade que o assobérba, procurará conduzir este "quarto estado" a que se referia, ha poucos dias nesta mesma Faculdade o professor Guido de Ruggiero, da Universidade de Roma (5) e que óra surge no cenário politico nacional, sinão no plano internacional, turbulento e combativo, cheio de aspirações, clamando reivindicações, tendendo mesmo, sob o influxo de ideologias exóticas que talvez só germinem em climas glaciaes, a se hipertrofiar em tal escala que já se pregou até a ditadura do proletariado...

Si em 1789, o Abade Sièyes, em famósa brochura que é a formula da Revolução, analisou o "terceiro estado": Qu'est ce que le tiers etát? Tout. Qu'a t'il été jusqu'a present dans l'ordre politique? Rien. Que demande t'il? A y devenir quelque chose. ", hoje vemos deste mesmo "terceiro estado", amalgama de burgueses, artesãos e camponeses, se destacar o "quarto estado", o proletariado, palpitante avalanche em que a "Maquina" transformou o artesanato, e que deve ser dirigido para que alcance suas justas aspirações, aprendendo a separar o joio do trigo, a se aper- 
ceber quão nefasta e perigósa é a demagogia que incita mas não realisa, a descrer de falsos profetas tão vasios de sinceridade quão enxundiosos de promessas, a desconfiar destes paraizos orientaes que suspeitósamente se escondem de vistas profanas atraz de "cortinas de ferro" sem querer evidenciar ao mundo suas proclamadas realisações.

Bem sei que a famósa questão social, a que LEÃo XIII, Ziegler, Gianturco, Novicov, Willey, Schaffle, Vazeille, Keteller, Posadas e Bourgeors, Azcarate, Stein e Wuarin (6) emprestam tão polimôrfo conteudo é eterna como a vida, pois viver é lutar; bem sei que a humanidade sempre viveu, vive e viverá insatisf eita, o que, penso ser um bem, pois sua jnsaciedade é sintoma de que almeja um ideal. .

Si este, considerado como a realidade sem suas imperfeições, é inatingivel pelo homem, a tendencia para o realisar é decisivo fator de progrésso que entretanto só se verificará si os meios empregados forem idôneos.

V. excia., Snr. Ministro do Trabalho, vae justamente discorrer sobre "O Ideal Social na Democracia" e quér me parecer que esta é na verdade o meio adequado para que d'aquele nos aproximemos.

Advogado militante bem conhece V. Excia. as paixões humanas, tem o senso da realidade, a experiencia que se começa a adquirir no inicio da carreira, nas escaramuças das Justiças de Paz e se aperfeiçoa e se aprimora nas grandes pelejas que costumam ter seu "Austerlitz" ou seu "Waterloo" no mais alto Tribunal do País.

Tem noção clara e precisa da realidade da vida sem contudo perder, jurista que é, o amor ao Ideal pois a propria Justiça, como diz Mortara (7) é um conceito ideal a contrastar com a imperfeição humana.

Foi o trabalho a alavanca de sua brilhante carreira: pertence pois, de um certo modo, a este famoso "quarto estado" e como este bem compreende o que o trabalho déve proporcionar ao que trabalha... 
Exemplo vivo de operosidade ha-de ensinar porenx como pelo trabalho se obtem sucésso: pelo zelo no exercicio da profissão, pela realisação conciente de seus mistéres, pela escravisação voluntária ao cumprimento do dever.

Desvendando esse segredo, certamente, pelo exemplo, levará todos os que trabalham a compreender que o amor apaixonado à profissão ou oficio que conduz à perfeição na arte e a vitória na ciencia, importará, no plano económico, no aumento da produção e da riqueza, formula mais eficaz talvez, pelo barateio das of elimidades para acarretar euforia financeira ao operário do que o aumento continuo de salarios, com seus reflexos e repercussões.

E' esta formula, na verdade, uma resultante do conceito juridico de que ha direitos e obrigações e que aqueles só pode exigir quem estas haja cumprido.

Si o Estado déve amparo ao operário, este the déve aquilo que constitue o verdadeiro civismo: o seu concurso leal na óbra magnifica do soerguimento da Patria quando não o seu sacrificio nos momentos de angustia e de necessidade publica.

A Idade Média, a que Emerson e Tobias Barreto tantos encomios teceram, devemos pedir de emprestimo esse fator de progrésso que é o esmero, o carinho, o desvelo na execução da tarefa que então se incutia no aprendiz, se aprimorava no companheiro para que atingisse o requinte do Mestre. .

Este o segredo do sucésso na vida. .

Snr. Ministro Honório Monteiro.

Paulista, leva V. Excia. para o Ministério do Trabalho tesouro dos mais preciósos da terra bandeirante, joia que tem como escrinio o coração dos paulistas.

E' um lema!

Lema que bem demonstra que si nós paulistas temos cometido o nefando crime de amarmos com demasia nosso torrão natal, é porque estremecemos o Brasil. 
Lema que mão sacrilega alguma conseguirá jamais esmagar ou siquér macular . (8)

Lema que São Paulo escreveu no sólo bandeirante com o sangue de seus filhos, enalteceu com tanta bravura, emoldurou com o ouro de suas alianças, ungiu com tantas lagrimas femininas.

Lema que aqui nas Arcadas já antes ecoava nas vózes e acordes do Hino Academico.

Lema em que São Paulo, em hora de bravura e de desespero, de altivez e de sofrimento, cercado por todos os lados, justamente em cruenta luta pela reconstitucionalisação do país, em pleno fragor de batalha fratricida a todos conclamava em prol do Brasil.

Lema que ha-de polarisar a nação inteira, governantes e governados, ricos e pobres, patrões e empregados, todos irmanados no mesmo amor à Patria comum.

Lema que é a sublimação de nosso amor, de nossas lagrimas, de nosso sangue na luta pela Democracia:

"Pro Brasilia fiant eximia", (10) snr. Ministro!

\section{REFERENCIAS BIBLIOGRÁFICAS}

1 - Professor Mario Mazagão - Discurso de paraninfo à turma de bacharelandos de 1943, da Faculdade de Direito da Universidade de São Paulo.

2 - Mihail Manoilesco - " Le parti unique".

3 - Alusão à formatura de um filho do snr. Ministro do Trabalho, o dr. Helladio de Toledo Monteiro, hoje seu oficial de gabinete.

4 - Siqueira Ferreira - Discurso de paraninfo à turma de bacharelandos de 1947, da Faculdade de Direito da Universidade de São Paulo.

5 - Conferencia realisada na Faculdade de Direito da Universidade de São Paulo, em 29 de Setembro de 1948.

6 - José Martinez Santoja - "El problema social", Madrid, 1927, apud Martin Granizo e Gonzales Rothyoss - "Derecho social", Madrid, 1932. 
7 - Ludovico Mortara - "Lo Stato moderno e la giustizia".

8 - Alusão ao ato da ditadura extinguindo bandeiras, brazões e disticos dos Estados Brasifeiros e á tentativa de se atribuir aos revolucionários paulistas pedido de intervenção estrangeira.

9- "Mocidade, eia avante, eia avante! Que o Brasil sobre vós ergue a fé;

Esse imenso colosso gigante

Trabalhae por ergue-lo de pé! - trecho do Hino Academico da lavra de Bittencourt Sampato e Musica de Carlos Gomes. Conf. Spencer Vampré - Memórias para a História da Academia de São Paulo, Livraria Academica, São Paulo, sem data, 1.0 vol. pag. 490.

10 - Decreto 5.656 de 29 de Agosto de 1932, em plena epopéa constitucionalista. Conf. Clovis Ribeiro - Brazões e Bandeiras do Brasil, São Paulo, 1933, pag. 204. 